\title{
Factors affecting utilization of skilled maternal care in Northwest Ethiopia: a multilevel analysis
}

\author{
Abebaw Gebeyehu Worku ${ }^{1 *}$, Alemayehu Worku Yalew² and Mesganaw Fantahun Afework ${ }^{3}$
}

\begin{abstract}
Background: The evaluation of all potential sources of low skilled maternal care utilization is crucial for Ethiopia. Previous studies have largely disregarded the contribution of different levels. This study was planned to assess the effect of individual, communal, and health facility characteristics in the utilization of antenatal, delivery, and postnatal care by a skilled provider.

Methods: A linked facility and population-based survey was conducted over three months (January - March 2012) in twelve "kebeles" of North Gondar Zone, Amhara Region. A total of 1668 women who had births in the year preceding the survey were selected for analysis. Using a multilevel modelling, we examined the effect of cluster variation and a number of individual, communal (kebele), and facility-related variables for skilled maternal care utilization.

Result: About 32.3\%, 13.8\% and $6.3 \%$ of the women had the chance to get skilled providers for their antenatal, delivery and postnatal care, respectively. A significant heterogeneity was observed among clusters for each indicator of skilled maternal care utilization. At the individual level, variables related to awareness and perceptions were found to be much more relevant for skilled maternal service utilization. Preference for skilled providers and previous experience of antenatal care were consistently strong predictors of all indicators of skilled maternal health care utilizations. Birth order, maternal education, and awareness about health facilities to get skilled professionals were consistently strong predictors of skilled antenatal and delivery care use. Communal factors were relevant for both delivery and postnatal care, whereas the characteristics of a health facility were more relevant for use of skilled delivery care than other maternity services.
\end{abstract}

Conclusion: Factors operating at individual and "kebele" levels play a significant role in determining utilization of skilled maternal health services. Interventions to create better community awareness and perception about skilled providers and their care, and ensuring the seamless performance of health care facilities have been considered crucial to improve skilled maternal services in the study area. Such interventions should target underprivileged women.

Keywords: Skilled maternal care, Linked survey, Multilevel analysis

\section{Background}

In Ethiopia, maternal health has received attention for the last two decades. Currently, reducing maternal mortality is one of the goals of the Health Service Development Program of the country. Maternal and newborn health is also among the six priority areas in the reproductive health strategy [1]. Based on ecological and historical evidences observed in European and Asian countries,

\footnotetext{
* Correspondence: abebawgebeyehu@yahoo.com

'Department of Reproductive Health, Institute of Public Health, University of Gondar, Gondar, Ethiopia

Full list of author information is available at the end of the article
}

health professionals with midwifery skill were considered the key factors to decrease maternal mortality. The low maternal mortality rates reported by the Netherlands, Norway, and Sweden in the early 20th century were believed to have been the result of an extensive collaboration between physicians and highly competent, locally available midwives [2]. Similarly, Malaysia, Sri Lanka and Thailand halved their maternal mortality ratios within ten years by increasing the number of midwives in the 1950s and 1960s [3].

\section{Biomed Central}

(c) 2013 Worku et al.; licensee BioMed Central Ltd. This is an Open Access article distributed under the terms of the Creative Commons Attribution License (http://creativecommons.org/licenses/by/2.0), which permits unrestricted use, distribution, and reproduction in any medium, provided the original work is properly cited. 
At the moment, many countries including Ethiopia are working to meet the WHO recommendation of having skilled attendance for all births [4]. According to the recent 2011 Ethiopian Demographic and Health Survey (EDHS) report, only 34\%, $10 \%$ and $6 \%$ of the women had Antenatal Care (ANC), delivery, and postnatal care by skilled providers respectively [5]. Maternal mortality has also not changed from its previous level where maternal mortality ratio was 673 per 100,000 live births in the 2005 EDHS report [6], and it was 676 per 100,000 live births in the 2011 EDHS report [5].

Skilled maternal care refers to maternity services (antenatal, delivery, and postnatal care) by a health professional with midwifery skill that can be provided at different levels (home, health centers or hospitals). In order to provide such skilled maternal care, we need to have an enabling environment and skilled providers. An enabling environment include; functional health facilities and a reliable referral system to link the different levels, awareness and readiness of the community for utilizing skilled care as well as supporting the policy and political commitment [4]. Health professionals who have been educated and trained to proficiency in the skills needed to manage normal pregnancies, childbirth and the immediate postnatal period, and in the identification, management or referral of complications are categorized as skilled care providers $[7,8]$. In the study, skilled providers include midwives, nurses, health officers and doctors.

There are several factors influencing skilled maternal health care utilization within the dimensions of skilled maternal care definition. The factors operate their impact at different levels. Review of the global literature indicates that these factors can be classified as 1) individual and household level 2) communal and health facility level and 3) national or state level.

At the individual and household level maternal education, parity, residence, awareness and perceptions related to the risks of pregnancy and skilled maternal services, previous experiences, women's decision-making power, and household wealth are some of the known variables.

At the health facility level the availability, readiness, and quality of services as well as the type, competence and caring behavior of providers are very important for maternal services. However, in many developing countries health facilities are not performing the expected functions according to their level [9]. Furthermore, there is a huge gap in the competence of health workers categorized as skilled providers $[8,10]$. Pre-service training is also not a guarantee. It is recommended that maternity care providers need to receive refresher training or updates in midwifery every three to five years [11].

Some studies identified community and state level factors using multilevel analysis. A study in Vietnam reported that the presence of low education coverage, geographical isolation, and high poverty rate in the community reduce access to skilled maternal services [12]. Evidences from Nigeria also showed that urban residence and the availability of community media significantly increased maternal service utilization [13]. At the policy level, resource investments in the main system components of health programs raised the level of maternal service utilizations [14]. The significant effect of government health expenditure in improving the utilization of skilled maternal service was also observed in other studies $[15,16]$.

Studies in Ethiopia have serious limitations in evaluating the determinants of skilled maternal care utilization. The studies provided evidence based on the evaluation of either user or facility related determinants. Addressing only one of these categories is likely to present a very incomplete picture of the evaluation of determinants affecting maternal service utilization. In addition, the nesting effects of different levels are usually not controlled during analysis. Therefore, appropriate methodology is required for a more comprehensive and accurate analysis. As a result, all potential sources of poor skilled maternal care utilization can be evaluated to design maternal service strategies at different levels. This study was planned to assess the effect of individual, household, communal and health facility characteristics in the utilization of antenatal, delivery, and postnatal care by a skilled provider.

\section{Methods}

\section{Study design and area}

A linked facility and population-based survey i.e. a facility survey linked to population based survey sample areas was conducted over three months (January - March 2012) in North Gondar Zone. The two surveys were conducted concurrently to analyze all potential factors operating at different levels (individual and community levels) simultaneously. The use of linked survey is also considered as stronger approach to analyze causality in nonexperimental studies [17].

North Gondar is one of the 11 zones of the Amhara Regional State located in northwest Ethiopia. It has 22 districts. The zonal center, Gondar town, is located 735 kilometer from Addis Ababa. At the time of the study, more than three million individuals were living in the zone. About $84.1 \%$ of its inhabitants were rural dwellers [18]. North Gondar, the largest zone of the region, is known for its difficult topography.

\section{Study population and sampling}

Women who had births in the year preceding the survey were included in the study. A multistage sampling technique was applied to select the study population. Initially, six districts of the zone namely Dembia, Lay Armachiho, West Belessa, Metema, Debark and Dabat 
were selected. Then a total of twelve clusters or kebeles (two kebeles per district) were selected randomly. The 'kebeles' are the lowest administrative units with a size of about 1000 households (5000 population). All eligible women found in the selected cluster were studied. Accordingly, 1730 women were identified for interview.

The adequacy of the sample size was checked based on differences in frequency of important exposure variables among users and non-users at the time of proposal development. Epi Info StatCalc software was used for the calculations by assuming a $95 \%$ confidence level and $80 \%$ power with a 1:3 ratio of users and non-users.

In order to have a linked data, basic essential obstetric care facilities (health centers) utilized by the kebele population were selected for the facility based survey. For each cluster (kebele), one basic essential obstetric care facility was studied and linked.

\section{Data collection}

All health facilities serving the study population were assessed with regard to the number, training and competency of obstetric staff; services offered; signal functions; physical infrastructure; and availability, adequacy and functional status of supplies and other essential equipment for maternal services. The basic signal functions include parenteral antibiotics, anticonvulsants and oxytocics, and the procedures for manual removal of the placenta, removal of retained uterine products, and assisted vaginal delivery. During the population based survey information about kebele (cluster) characteristics, socio-demographic characteristics, awareness, perceptions and experiences related to the women's use of skilled maternal care services were collected.

For the population based survey, a total of 36 qualified data collectors and supervisors (2 data collectors and 1 supervisor for each kebele) were trained and deployed. The interviews were conducted using the local language (Amharic) after the questionnaire was pretested for cultural appropriateness and clarity. For the facility-based survey, 14 health professionals who had work experience were recruited.

\section{Data analysis and modeling}

After appropriate coding, the data were entered using Epi Info version 3.5.3 software and exported to STATA version 11 software for analysis. Uses of maternal services (antenatal, delivery and postnatal care) by skilled providers were the dependent variables. The predictors of each of these indicators were assessed separately using a multilevel binary logistic regression.

The rationales for using a multilevel modeling were the following. Firstly, the utilization patterns of maternal health services are influenced by the characteristics of different levels (individuals, community, and health facilities). Analyzing variables from different levels at one single common level using the standard binary logistic regression model leads to bias (loss of power or Type I error). This approach also suffers from a problem of analysis at the inappropriate level (atomistic or ecological fallacy). Multilevel models allow us to consider the individual level and the group level in the same analysis, rather than having to choose one or the other. Secondly, due to the multistage cluster sampling procedure, individual women were nested within kebeles; hence, the likelihood of women seeking maternal health services is likely to be correlated to the kebele members. The assumption of independence among individuals within the same cluster and the assumption of equal variance across clusters are violated in the case of nested data. Hence, the multilevel analysis is the appropriate method for such cases.

Using a two-level binary logistic regression modelling, we examined the effect of a number of individual, community, and facility variables. During analysis, the characteristics of women and household were taken as individual level (level-1), and characteristics of the kebeles (including characteristics of their health centers) were treated as level-2 (Table 1). For each of the three dependent variables, we estimated two models: intercept-only model; an empty model that contains no covariates, and a full model that included individual and kebele level variables. The full model was a random slopes model for ANC and a random intercept model for delivery and postnatal care.

Assume the binary responses $Y_{\mathrm{ij}}$ depend on individuallevel explanatory variable $X_{i j}$ and group-level explanatory variable $Z_{j}$. If deviation from the average intercept and slope due to cluster (level-2) effect are represented by $\boldsymbol{u}_{\mathbf{0} j}$ and $\boldsymbol{u}_{\mathbf{1}}$, the two models are given in the following way.

The intercept-only model $=$ Logit $p_{i j}=\gamma_{00}+u_{0 j}$ and the full model $=\operatorname{Logit}\left(p_{i j}\right)=\gamma_{00}+\gamma_{01} Z_{j}+\gamma_{10} X_{i j}+u_{0 j}+u_{1 j} X_{i j}$. The intercept $\gamma_{00}$ and slopes $\gamma_{01}$ and $\gamma_{10}$ are fixed effects whereas $\boldsymbol{u}_{\boldsymbol{o}}$ and $\boldsymbol{u}_{\mathbf{1} j}$ are random effects of level-2.

The intercept-only model allows us to evaluate the extent of the cluster variation influencing maternal service utilization of women. The intra-class correlation coefficient (Rho) was calculated to evaluate whether the variation in the scores is primarily within or between clusters. In logistic distribution, level-1 residual variance, $\varepsilon_{\mathrm{ij}}$, is standardized and fixed with a mean of zero and variance $=\pi^{2} / 3$. Therefore, for a two-level logistic random intercept model with an intercept variance of $\sigma_{\mathrm{u} 0}^{2}$, the intra-class correlation coefficient (Rho) is given by ' $\rho=\frac{\sigma^{2} \text { u } 0}{\sigma^{2} \text { и }+\pi^{2} / 3}$ '.

\section{Ethical considerations}

Before the commencement of the study, ethical clearance was obtained from the Institutional Review Board of the 
Table 1 Description and measurement of variables included in the models, North Gondar, 2012

\begin{tabular}{l} 
Variables \\
\hline Dependent variables \\
ANC, Birth attendance and PNC by a skilled \\
provider (three dependent variables)
\end{tabular}

provider (three dependent variables)

\section{Level-1 predictor variables}

Birth order

Maternal and husband educational status

Wealth quintile

Awareness on risk of pregnancy

Health professionals preferred by women

Awareness on places to get skilled providers

Pregnancy wontedness

ANC in previous pregnancy

Agreed on postnatal check up

\section{Level-2 predictor variables}

Source of income

Self sustained

Average distance

Presence of signal functions

Duty service

Availability of obstetric guidelines

Payment requirements

\section{Descriptions}

Women who received ANC at least once from a skilled provider, delivery attended by a skilled provider and Women who received PNC at least once from a skilled provider

\section{Individual and household characteristics}

Birth order of women's most recent birth (index birth)

Highest level of education attained by the respondent (mother) and her husband

Household wealth status is computed by principal component analysis from ten variables (presence of own farmland, own toilet facility, bank account, mobile phone, electricity, roof of house with corrugated iron sheet, number of cows/oxen, horses/ mules/donkeys goats/sheep and chicken)

Awareness of women on risk of pregnancy

Women prefer health professionals for their maternity care

Women know appropriate health facilities to get skilled providers

Pregnancy wanted or not

Presence of at least one ANC visit in previous pregnancies

Women agreed on the need of postnatal check up after normal delivery

\section{Communal (kebele) characteristics}

The kebele population main source of income

Presence of enough production for feeding the population

Average distance (in Kilometer) of villages in each kebele to the nearest health center

\section{Health facility characteristics}

Presence of all the six signal functions in basic essential obstetric care facilities (health centers)

Maternity service for 24 hrs and 7 days

Obstetric guidelines available for reference by staff at all times

Maternity clients required to purchase/ provide supplies/drugs at time of delivery

\section{Measurements}

For each indicator, 'Yes' responses are coded as ' 1 ' otherwise as ' 0 '

It is divided in to four categories: first birth, 2nd-3rd, 4th-5th and above 5 th

For each variable, it is categorized in to three: illiterate, primary and secondary and above secondary

The wealth status is categorized in to five groups and ranked from poorest to wealthiest quintile.

When women mentioned at least one major risk factor, the value is ' 1 ' if not it is ' 0 '

Yes' responses are coded as ' 1 ' and no responses as ' 0 '.

When appropriate facilities are known, the value is ' 1 ' if not it is ' 0 '.

Pregnancy wanted or miss-timed coded as ' 0 ' and unwanted coded as ' 1 '

Yes' responses are coded as ' 1 ' and no responses as ' 0 '.

When women agreed, the value is ' 1 ' if not it is ' 0 '.

It is categorized in to two: Farming and mixed (farming and trading)

Yes' responses are coded as ' 1 ' and no responses as ' 0 '.

Supervisors estimated the distances of villages from health centers. The average values were calculated and rounded to one decimal place.

If all signal functions are present, the value is labeled as ' 1 ' if one or more are missing, the value is labeled as ' 0 '

Yes' responses are coded as ' 1 ' and no responses as ' 0 '.

Yes' responses are coded as ' 1 ' and no responses as ' 0 '.

Yes' responses are coded as ' 1 ' and no responses as ' 0 '. 


\section{Table 1 Description and measurement of variables included in the models, North Gondar, 2012 (Continued)}

\begin{tabular}{|c|c|c|}
\hline Overall infrastructure & $\begin{array}{l}\text { Infrastructures of the health facility } \\
\text { (examination and delivery rooms, } \\
\text { refrigerator, water source, power supply, } \\
\text { toilet facilities, drainage system...) }\end{array}$ & $\begin{array}{l}\text { Based on records of observation, } \\
\text { the infrastructure of the health } \\
\text { facility is categorized as not } \\
\text { satisfactory (1) and satisfactory (2). }\end{array}$ \\
\hline Basic equipments & $\begin{array}{l}\text { Presence of basic equipments } \\
\text { (BP apparatus, stethoscope, fetal } \\
\text { stethoscope, adult and baby } \\
\text { weighing scales, delivery and } \\
\text { episiotomy sets, sterilizers...) }\end{array}$ & $\begin{array}{l}\text { Based on records of observation, } \\
\text { the variable is categorized as not } \\
\text { satisfactory (1) and satisfactory (2). }\end{array}$ \\
\hline
\end{tabular}

College of Health Sciences, Addis Ababa University. Then permission letters from officials of districts and health institutions were processed before starting data collection. During data collection, study participants were asked for consent and were signed written agreements on consent forms. They were informed to interrupt the interview on desire. To ensure confidentiality, names were not used, instead code numbers were assigned to depict the results and the questionnaires were kept locked.

\section{Results}

A total of 1730 women were interviewed. For analysis, 1668 women were considered because some 62 copies of questionnaire were excluded during the data cleaning process due to incompleteness and inconsistent values. Majority of the study subjects was Orthodox Christians (93.7\%), Amhara by ethnicity (92.7\%) and currently married (92.7\%). At the time of their last birth, about $73.3 \%$ were between 20-34 years, 5.5\% were teenagers (less than 20 years) and $21.2 \%$ were elderly gravid (35 years and above). The mean age was $28.2 \pm 6.6$ years, with a range of $16-51$ years. The majority of the mothers $(71 \%)$ and their husbands (63.4\%) had no formal education (Table 2).

About 32.3\% (95\% CI, 30.0\%, 34.5\%), 13.8\% (95\% CI, $12.2 \%, 15.5 \%)$ and $6.3 \%$ (95\% CI, $5.1 \%$ to $7.5 \%)$ of women used antenatal, delivery and postnatal care by skilled providers, respectively. The bivariate analysis indicated that use of all indicators of skilled maternal services appeared to increase significantly with educational status of women and their husbands. Moreover, higher wealth quintiles, awareness of risk of pregnancy, preference for skilled provider, awareness about health facilities to get skilled professionals and previous experience of antenatal care showed a significant and positive association while higher birth order, and unwanted pregnancy showed a negative association in all maternal service indicators (Table 2).

The multilevel analysis was started from the interceptonly model to test the null hypothesis that there is no variation in maternal health services utilization between clusters (kebeles) and to decide in evaluation of the random effects at the community level. The results presented in Table 3 indicated that considerable heterogeneity between kebeles was observed for each indicator of skilled maternal care utilization. In all the three indicators, use of service is clustered significantly by kebele. The intra-class correlation in the empty model for antenatal, delivery and postnatal care by skilled provider indicated that 31\%, $12 \%$, and $25 \%$ of the total variance in use of the services was attributable to the differences across kebeles (Table 3).

\section{Antenatal care by a skilled provider}

Maternal education, preference for skilled provider, awareness about health facilities to get skilled professionals and previous experience of antenatal care were strong individual level predictors of the recent antenatal care by a skilled provider. The predictor 'birth order' indicates that women tend to use antenatal care by a skilled provider if their birth is their first time, and a small but significant difference was observed compared with those women with four or five births. The odds ratio indicates that use of antenatal services initially decreases with birth order up to the third category and increases thereafter.

Antenatal care by a skilled provider increases steadily with education so that women with secondary and above education were $68 \%$ more likely to use service as their counterparts with no education. Women who have had at least one antenatal care in previous pregnancies were about three times more likely to use skilled antenatal care for their recent pregnancy. Similarly, women who preferred health professionals for their maternity care and have awareness about health facilities to get skilled professionals significantly use skilled antenatal care compared with their counterparts.

The study further showed that communal level variables included in the model were not significant predictors of skilled antenatal services utilization.

Finally, a substantial proportion of the between kebele variance was explained by this model given the between kebele variation has been reduced from 1.52 to 0.76 , a $50 \%$ reduction in unexplained variance between kebele ANC utilization. However, community level random effects are significant; the residual intra-class correlation is still appreciably large, indicating that even after controlling for individual, communal (kebele) level factors, there is still a considerable clustering of antenatal service utilization 
Table 2 Utilization of skilled maternal health services using selected individual level characteristics, North Gondar, 2012

\begin{tabular}{|c|c|c|c|c|c|}
\hline \multirow[t]{2}{*}{ Characteristics } & & \multirow[t]{2}{*}{$\mathbf{n}$} & \multicolumn{3}{|c|}{$\begin{array}{l}\text { Number (percent) of women reporting } \\
\text { skilled provider for: }\end{array}$} \\
\hline & & & ANC & Delivery care & PNC \\
\hline \multirow[t]{4}{*}{ Birth order } & 1 & 335 & $132(39.4)$ & 77 (23.0) & $31(9.3)$ \\
\hline & $2-3$ & 657 & $215(32.7)$ & $85(12.9)$ & $47(7.2)$ \\
\hline & $4-5$ & 439 & $116(26.4)$ & $43(9.8)$ & $17(3.9)$ \\
\hline & $6+$ & 237 & 75 (31.6) & $26(11.0)$ & $10(4.2)$ \\
\hline \multirow[t]{3}{*}{ Mother's education } & No education & 1183 & $339(28.7)$ & $129(10.9)$ & $56(4.7)$ \\
\hline & Primary & 327 & $117(35.8)$ & $49(15.0)$ & $24(7.3)$ \\
\hline & Secondary and above & 158 & $82(51.9)$ & $53(33.5)$ & $25(15.8)$ \\
\hline \multirow[t]{3}{*}{ Husband education } & No education & 1057 & $286(27.1)$ & $116(11.0)$ & $50(4.7)$ \\
\hline & Primary & 430 & $172(40.0)$ & $62(14.4)$ & $33(7.7)$ \\
\hline & Secondary and above & 181 & $80(44.2$ & $53(29.3)$ & $22(12.2)$ \\
\hline \multirow[t]{5}{*}{ Wealth quintile } & Lowest & 331 & $81(24.5)$ & $37(11.2)$ & 13(3.9) \\
\hline & Second & 340 & 107 (31.5) & $43(12.6)$ & $15(4.4)$ \\
\hline & Middle & 306 & $112(36.6)$ & $44(14.4)$ & $30(9.8)$ \\
\hline & Fourth & 357 & $128(35.9)$ & $60(16.8)$ & $24(6.7)$ \\
\hline & Highest & 334 & $110(32.9)$ & $47(14.1)$ & $23(6.9)$ \\
\hline \multirow[t]{2}{*}{ Women have awareness on risk of pregnancy } & No & 522 & $90(17.2)$ & $52(10.0)$ & $13(2.5)$ \\
\hline & Yes & 1146 & $448(39.1)$ & $179(15.6)$ & $92(8.0)$ \\
\hline \multirow[t]{2}{*}{ Women preferred health professionals for the care } & No & 713 & $142(19.9)$ & $40(5.6)$ & $15(2.1)$ \\
\hline & Yes & 955 & $396(41.5)$ & $191(20.0)$ & $90(9.4)$ \\
\hline \multirow[t]{2}{*}{ Women have awareness on places to get skilled providers } & No & 341 & $45(13.2)$ & $14(4.1)$ & $7(2.1)$ \\
\hline & Yes & 1327 & $493(37.2)$ & $217(16.4)$ & $98(7.4)$ \\
\hline \multirow[t]{2}{*}{ Pregnancy wontedness } & Wanted/mistimed & 1511 & $495(32.8)$ & $214(14.2)$ & $96(6.4)$ \\
\hline & Unwanted & 157 & $43(27.4)$ & $17(10.8)$ & $9(5.7)$ \\
\hline \multirow[t]{2}{*}{ ANC in previous pregnancy } & No & 957 & $200(20.9)$ & $107(11.2)$ & $42(4.4)$ \\
\hline & Yes & 711 & $338(47.5)$ & $124(17.4)$ & $63(8.9)$ \\
\hline \multirow[t]{2}{*}{ Women agree on planning health institutions as delivery place } & No & 432 & & $38(8.8)$ & \\
\hline & Yes & 1236 & & $193(15.6)$ & \\
\hline \multirow[t]{2}{*}{ ANC for this pregnancy by a skilled provider } & No & 1130 & & $103(9.1)$ & $56(5.0)$ \\
\hline & Yes & 538 & & $128(23.8)$ & $49(9.1)$ \\
\hline \multirow[t]{3}{*}{ Women agree to have PNC after normal delivery } & No & 767 & & & $26(3.4)$ \\
\hline & Yes & 901 & & & 79 (8.8) \\
\hline & Total & 1668 & $538(32.3)$ & 231 (13.8) & $105(6.3)$ \\
\hline
\end{tabular}

at the community (kebele) level. The between kebele variance of slopes indicated that the two variables, ANC in the previous pregnancies and preference for skilled providers, significantly varied across kebeles. That means, the relationships between these variables and ANC use by women were different for different kebeles (dependent on the proportion of ANC users in the kebeles) (Table 4).

\section{Delivery care by a skilled provider}

The significant individual level variables that predict use of delivery care by a skilled provider include; birth order, maternal education, preference for skilled provider, awareness about health facilities to get skilled professionals, experience of antenatal care for previous pregnancies and skilled antenatal care for the recent pregnancy. Women who had births for the first time were more likely to use skilled birth attendance compared with any of the birth order categories, and the difference was statistically significant in all comparisons. As we observed with the use of antenatal care, skilled attendance at birth increases significantly with secondary education. Women having at least one antenatal care in previous pregnancies or skilled 
Table 3 Parameter coefficients of the intercept-only model in using skilled maternal care, North Gondar, 2012

\begin{tabular}{cccc}
\hline & ANC by skilled provider & Birth attendance by skilled provider & PNC by skilled provider \\
\hline Random effects & & & \\
Level 2 variance & $1.52^{*}(0.63,3.71)$ & $0.45^{*}(0.17,1.18)$ & $1.09^{*}(0.35,3.38)$ \\
Rho - Intra-class correlation & 0.31 & 0.12 & 0.25 \\
Deviance & 1832 & 1282 & 735 \\
\hline
\end{tabular}

*Significant.

antenatal care in their recent pregnancy were about two times more likely to have birth attendance by a skilled provider. Similar to the antenatal care service, women who preferred health professionals for their maternity care and have awareness about health facilities to get skilled professionals used significantly more delivery care by a skilled provider compared with their counter parts.

Three predictor variables from the second level, that is, source of income, signal function and payment requirements during delivery were significantly associated with skilled attendance at birth. Women who belonged to communities with mixed (farming and trading) source of income used skilled attendance $64 \%$ higher than those who belonged to only farming as the main source of income. The presence of all the six signal functions in the nearby basic essential obstetric care facility (health center) increased skilled attendance rate about two times compared to those health centers with at least one function is missing. By contrast, presence of payment requirements during delivery reduced utilization of skilled attendance by $47 \%$.

The random part of this model indicated that almost all of the between kebele variance was explained by the included variables in the model. The model fitness was also improved significantly (Table 4).

\section{Postnatal care by skilled attendant}

Three predictor variables, two from the individual level and one from the communal level significantly associated with postnatal care by a skilled provider. At the individual level, women who preferred skilled provider for their maternity care, and women who had experience of at least one antenatal care for their previous pregnancies used a skilled postnatal care more likely compared with those who did not have such characters.

At the communal level, the odds of postnatal care by a skilled provider significantly increased among women belonging to communities who had mixed (farming and trading) source of income compared with those belonging to only farming as the main source of income.

Like that of the skilled attendance at birth, the random part of the model indicated that almost all of the between kebele variance in the use of skilled postnatal care was explained by the variables in the model (Table 4).

\section{Discussion}

Using a linked population and facility based survey and appropriate modeling framework, this study assessed the effect of individual, household, communal and health facility characteristics in utilization of antenatal, delivery, and postnatal care by a skilled provider. The results suggest that utilization of skilled maternal care by individual women is very low in the study area. The finding is consistent with the recent EDHS report and previous studies conducted in the surrounding area $[5,19,20]$.

Our analysis indicates that utilization of skilled maternal care by individual women depends on the joint effect of individual, household, communal and facility characteristics. According to the intra-class correlation results, the contribution of unobserved communal level characteristics, were $31 \%$ for antenatal care, $12 \%$ for delivery care and $25 \%$ for postnatal care. In all the three intercept-only models, the contributions were significant and indicated that determining association without the control of variables at different levels would give a misleading result. This was also observed during analysis where many of the significant associations disappeared when the effect of clustering by kebele was controlled. Previous studies based on a similar analysis showed consistent findings $[12,13]$.

At the individual level, variables related to awareness and perceptions were found to be much more relevant for skilled maternal service utilization. Women may get knowledge on the importance of skilled maternal care in different ways such as previous exposure to skilled maternal services, community based health educations, through community media or due to their better educational status. In this study, women with at least one antenatal care in previous pregnancies were significantly more likely, to use skilled maternal care for all the three indicators of their recent pregnancy. The positive effect of maternal service in the previous birth on current maternal care was observed in different studies done elsewhere [12,21,22].

Having awareness about health facilities to get skilled professionals was a significant predictor of both skilled antenatal and delivery care. The effect of awareness was also observed in community-based interventions focusing on awareness creation. For example, in Ethiopia, higher rate of household visits and awareness by health extension and community health workers were associated with 
Table 4 Results of the multilevel analysis by predictors of skilled maternity care, North Gondar, 2012

\begin{tabular}{|c|c|c|c|c|c|}
\hline \multirow{2}{*}{\multicolumn{2}{|c|}{$\begin{array}{l}\text { Predictors } \\
\text { Level-1 predictor variables (Individual and household characteristics) }\end{array}$}} & \multirow{3}{*}{$\begin{array}{l}\mathbf{n} \\
335\end{array}$} & \multicolumn{3}{|c|}{ Adjusted odds ratio $(95 \% \mathrm{Cl})$} \\
\hline & & & \multirow{2}{*}{ ANC } & \multirow{2}{*}{$\begin{array}{r}\text { Delivery care } \\
1\end{array}$} & \multirow{2}{*}{$\frac{\text { PNC }}{1}$} \\
\hline Birth order & 1 & & & & \\
\hline & $2-3$ & 657 & $0.75(0.53,1.07)$ & $0.60(0.40,0.90)$ & $0.98(0.56,1.71)$ \\
\hline & $4-5$ & 439 & $0.66(0.44,0.99)$ & $0.51(0.32,0.85)$ & $0.58(0.28,1.20)$ \\
\hline & $6+$ & 237 & $0.79(0.50,1.25)$ & $0.55(0.31,0.96)$ & $0.60(0.26,1.38)$ \\
\hline \multirow{3}{*}{ Mother's education } & No education & 1183 & 1 & 1 & 1 \\
\hline & Primary & 327 & $1.09(0.80,1.50)$ & $1.17(0.79,1.72)$ & $1.31(0.76,2.24)$ \\
\hline & Secondary and above & 158 & $1.68(1.08,2.60)$ & $1.94(1.21,3.10)$ & $1.72(0.86,3.47)$ \\
\hline \multirow[t]{3}{*}{ Husband education } & No education & 1057 & 1 & 1 & 1 \\
\hline & Primary & 430 & $1.34(0.98,1.82)$ & $0.83(0.56,1.22)$ & $0.83(0.49,1.39)$ \\
\hline & Secondary and above & 181 & $1.22(0.77,1.94)$ & $1.27(0.77,2.11)$ & $0.85(0.43,1.70)$ \\
\hline \multirow[t]{5}{*}{ Wealth quintile } & Lowest & 331 & 1 & 1 & 1 \\
\hline & Second & 340 & $1.02(0.69,1.51)$ & $1.08(0.66,1.78)$ & $0.97(0.44,2.14)$ \\
\hline & Middle & 306 & $1.14(0.75,1.72)$ & $1.24(0.74,2.08)$ & $2.08(1.01,4.28)$ \\
\hline & Fourth & 357 & $1.03(0.68,1.56)$ & $1.51(0.92,2.46)$ & $1.35(0.63,2.86)$ \\
\hline & Highest & 334 & $0.83(0.54,1.27)$ & $1.21(0.71,2.05)$ & $1.44(0.67,3.13)$ \\
\hline \multirow[t]{2}{*}{ Awareness on risk of pregnancy } & No & 522 & 1 & 1 & 1 \\
\hline & Yes & 1146 & $1.35(0.96,1.89)$ & $1.10(0.82,1.75)$ & $1.52(0.79,2.93)$ \\
\hline \multirow[t]{2}{*}{ Health professionals preferred for the care } & No & 713 & 1 & 1 & 1 \\
\hline & Yes & 955 & $1.64(1.14,2.36)$ & $2.29(1.50,3.51)$ & $2.45(1.31,4.60)$ \\
\hline \multirow[t]{2}{*}{ Awareness on places to get skilled provider } & No & 341 & 1 & 1 & 1 \\
\hline & Yes & 1327 & $1.63(1.07,2.49)$ & $2.83(1.54,5.20)$ & $1.48(0.64,3.42)$ \\
\hline \multirow[t]{2}{*}{ Pregnancy wontedness } & Wanted/mistimed & 1511 & 1 & 1 & 1 \\
\hline & Unwanted & 157 & $0.79(0.51,1.22)$ & $0.59(0.34,1.03)$ & $0.67(0.31,1.42)$ \\
\hline \multirow[t]{2}{*}{ ANC in previous pregnancy } & No & 957 & 1 & 1 & 1 \\
\hline & Yes & 711 & $3.39(1.98,5.80)$ & $1.80(1.31,2.49)$ & $1.92(1.20,3.08)$ \\
\hline \multirow[t]{2}{*}{ Skilled ANC for this pregnancy } & No & 1130 & & 1 & 1 \\
\hline & Yes & 538 & & $1.90(1.37,2.63)$ & $0.76(0.48,1.20)$ \\
\hline \multicolumn{6}{|l|}{ Level 2 predictor variables } \\
\hline \multicolumn{6}{|l|}{ Communal (kebele) characteristics } \\
\hline \multirow[t]{2}{*}{ Main source of income } & Farming & 1214 & 1 & 1 & 1 \\
\hline & Mixed & 454 & $1.35(0.47,3.88)$ & $1.64(1.18,2.28)$ & $1.54(1.03,2.30)$ \\
\hline \multirow[t]{2}{*}{ Self sustained } & No & 445 & 1 & 1 & 1 \\
\hline & Yes & 1223 & $1.29(0.21,8.09)$ & & \\
\hline Average distance to the nearest health center & & & $0.83(0.46,1.48)$ & $0.84(0.69,1.03)$ & $0.80(0.63,1.02)$ \\
\hline \multicolumn{6}{|l|}{ Health facility characteristics } \\
\hline \multirow[t]{2}{*}{ Signal functions } & One or more missed & 583 & 1 & 1 & 1 \\
\hline & All present & 1085 & $1.14(0.24,5.51)$ & $1.96(1.13,3.40)$ & $1.16(0.58,2.35)$ \\
\hline \multirow[t]{2}{*}{ Availability of obstetric guidelines } & No & 900 & & & 1 \\
\hline & Yes & 768 & & & $1.13(0.59,2.18)$ \\
\hline \multirow[t]{2}{*}{ Payment requirements during delivery } & No & 1252 & & 1 & \\
\hline & Yes & 416 & & $0.53(0.32,0.88)$ & \\
\hline \multirow[t]{2}{*}{ Overall infrastructure } & Not satisfactory & 1153 & 1 & 1 & 1 \\
\hline & Satisfactory & 515 & $1.64(0.39,6.92)$ & $0.98(0.64,1.51)$ & $1.51(0.74,3.10)$ \\
\hline
\end{tabular}


Table 4 Results of the multilevel analysis by predictors of skilled maternity care, North Gondar, 2012 (Continued)

\begin{tabular}{|c|c|c|c|c|c|}
\hline \multirow[t]{2}{*}{ Basic equipments } & Not satisfactory & 878 & & 1 & \\
\hline & Satisfactory & 790 & & $1.12(0.73,1.72)$ & \\
\hline \multicolumn{6}{|l|}{ Random part } \\
\hline \multicolumn{2}{|r|}{ Var (ANC in previous preg) } & & $0.62(0.22,1.80)$ & - & - \\
\hline \multicolumn{2}{|r|}{ Var (Preference of $\mathrm{H}$. professionals for the care) } & & $0.07(0.14,4.05)$ & - & - \\
\hline \multicolumn{2}{|r|}{$\operatorname{Var}($ cons) i.e. level-2 variance } & & $0.76(0.41,2.21)$ & $5.64 \mathrm{e}-19$ & $2.13 e-18$ \\
\hline \multicolumn{2}{|r|}{ Rho - Intra-class correlation } & & 0.19 & Nearly 0 & Nearly 0 \\
\hline \multicolumn{2}{|r|}{ Deviance $\left(G^{2}\right)$} & & 1652 & 1167 & 670 \\
\hline
\end{tabular}

improved antenatal care use and postnatal care visits [23]. Better educational status is believed to be an important factor for better awareness and positive attitude related to maternal health service utilization. As expected, skilled maternal care during pregnancy, delivery, and postnatal period increased steadily with education. Women with secondary and above education were also significantly associated with antenatal and delivery care by a skilled provider. Previous studies support our findings [13,19,24,25].

One of the expected effects of knowledge about an issue is change on individual attitudes. Women who have confidence on skilled providers and their care tend to use maternal health services by a skilled provider. In our analysis, significantly higher utilization rate of all skilled maternal health service indicators was observed among women who perceive that health professionals are better and safer (prefer skilled providers) for their maternity care. The implications of this finding is that community based health education about the benefit of skilled maternal care by targeting women who prefer non-skilled providers as well as improving the quality of care by providers will bring a positive contribution for utilizing skilled maternal care.

The predictor birth order indicates that women tend to use skilled maternal care if their birth is the first, and its significant effect is observed in antenatal and delivery care. The variations observed in the odds ratios can be related with the risk perception of women that varies overtime. Many women (48.3\%) believe the first pregnancy is risky compared with the next consecutive pregnancies. However, as the number of pregnancies exceeds a certain limit, they start to think about another risk. Because of this, many women $(41.3 \%)$ believe that having too many births is risky for a woman.

Women's health seeking behavior is also influenced by the cost of maternity services and their capacity to cover the expected expenses. For instance, a substantial proportion of antenatal care users did not deliver or use postnatal care by a skilled provider. On the one hand, maternity services, especially delivery care, are expensive. Studies indicate that delivery care use among antenatal care users is highly correlated with wealth [26]. On the other hand, delivery occurs suddenly. As a result, women have home birth by non-skilled providers due to transportation problems and lack of preparation. The positive contribution of better wealth status for all maternity service indicators and its significant contribution to postnatal care are also observed in our analysis. The study further evaluated the contribution of wealth indicators at kebele level. Women living in kebeles with mixed (farming and trading) source of income were utilizing significantly more skilled delivery and postnatal care than those living on farming only. The finding indicates that the presence of different sources of income for covering payments of transportation and other services contributed to the existence of higher rate of expensive maternal services in the communities. In this study, payment requirement at the time of delivery was an important barrier to delivery service by a skilled provider. The negative effect of the cost of maternity services and the need for reducing it was also observed in a study conducted in Tanzania. In the Tanzania study, standard maternity services were costly. For most households, maternal health care could take more than half of their annual consumption. The study further indicated that by subsidizing maternity care, women, especially those in the lowest socio-economic category would experience the greatest increase in service utilization [27]. The findings of our study and previous evidences imply that for better achievements in the utilization of skilled maternal health services, there should be mechanisms to reduce or avoid the costs of maternal services.

Another strong facility level predictor for skilled maternal care utilization was the performance of health facilities. The presence of all the six signal functions in the nearby basic essential obstetric care facility (health center) positively contributed to the utilization of all indicators of skilled maternal services, and its effect was significant on skilled attendance rate. Functioning obstetric facility means performing the essential services for normal situations and complications and these services should be available 24 hours a day and 7 days a week. The presence of all signal functions reflects better performance (quality) of a health facility. Furthermore, 
the findings of this study imply that improving the quality of care and monitoring facilities to perform the expected function at their level will be one of the strategies to increase the utilization rates of maternity care by a skilled provider.

\section{Limitations}

One of the limitations of this study was that women faced difficulties to differentiate the type of skilled providers during interview. To reduce the problem, data collectors gave further clarifications by collecting information on types of providers (doctor, health officer, nurse, midwife, health extension worker or others) from health institutions that gave services. Errors may occur in knowing the categories of health professionals. However, there were no serious difficulties in categorizing service providers as skilled or non-skilled, so it did not affect the interpretation of results. The potential limitations expected during analysis of determinant factors were minimized.

\section{Conclusions}

Factors operating at individual and communal (kebele) levels play a significant role in determining the utilization of skilled maternal health services, so controlling unexplained variations of the higher level is very important for preventing misleading associations. At the individual level, health-seeking behavior of a woman was more dependent on her awareness and perception on skilled provider or care. Included communal factors were relevant for both delivery and PNC. Health facility characteristics, including performance (functionality) and cost of service were more important for use of skilled delivery care than other maternity services. Improving community awareness and perception on skilled providers and their care by targeting women who prefer non-skilled providers and those who do not have any awareness is very important. Safe motherhood education using the available communication networks in the rural communities (health development army) and innovative informational campaigns are strategies to improve the intended awareness and perceptions of women. Furthermore, ensuring the seamless performance of basic essential obstetric care facilities (health centers) is also very critical, especially for improving the rate of skilled attendance at birth.

\section{Competing interests}

The authors declare that they have no competing interests.

\section{Authors' contributions}

All authors contributed equally during the process of proposal development. AG and AW participated in data collection and analysis. AG prepared the draft. Then AW and MF revised the drafts of the paper. All authors read and approved the final manuscript.

\section{Acknowledgements}

We are very grateful to Addis Ababa University for its technical and financial support. We would like to extend our heartfelt thanks to Professor Henry Mosley for his valuable comments starting from proposal development to the final manuscript preparation. We would also like to thank all of the study subjects who participated in this study for their commitment in responding to our interviews.

\section{Author details}

'Department of Reproductive Health, Institute of Public Health, University of Gondar, Gondar, Ethiopia. ${ }^{2}$ Department of Preventive Medicine, School of Public Health, Addis Ababa University, Addis Ababa, Ethiopia. ${ }^{3}$ Department of Reproductive Health and Health Service Management, School of Public Health, Addis Ababa University, Addis Ababa, Ethiopia.

Received: 4 November 2012 Accepted: 9 April 2013

Published: 15 April 2013

\section{References}

1. FDRE, MOH: National reproductive health strategy: 2006-2015. In Edited by Department of FH. Addis Ababa: Minstry of health; 2006.

2. Högberg U: The Decline in Maternal Mortality in Sweden. Am J Public Health 2004, 94(8):1312-1320.

3. Ronsmans C, Graham WJ: Maternal mortality: who, when, where, and why. Lancet 2006, 368(9542):1189-1200.

4. WHO: making pregnancy safer: the critical role of the skilled attendant. A joint statement by WHO, ICM, and FIGO. Geneva: Department of Reproductive Health and Research, World Health Organization; 2004.

5. Central Statistical Agency [Ethiopia], ICF international: Ethiopia demographic and health survey 2011. Addis Ababa, Ethiopia and Calverton, Maryland, USA: Central statistical agency and ICF international; 2012.

6. [Ethiopia] CSA, Macro O: Ethiopia Demographic and Health Survey 2005. Addis Ababa, Ethiopia and Calverton, Maryland, USA: Central statistical agency; 2006.

7. Carlough M, McCall M: Skilled birth attendance: what does it mean and how can it be measured? A clinical skills assessment of maternal and child health workers in Nepal. International journal of gynaecology and obstetrics: the official organ of the International Federation of Gynaecology and Obstetrics 2005, 89(2):200-208.

8. Harvey SA, Ayabaca P, Bucagu M, Djibrina S, Edson WN, Gbangbade S, McCaw-Binns A, Burkhalter BR: Skilled birth attendant competence: an initial assessment in four countries, and implications for the Safe Motherhood movement. Int J Gynecol Obstet 2004, 87(2):203-210.

9. Paxton A, Bailey P, Lobis S, Fry D: Global patterns in availability of emergency obstetric care. International journal of gynaecology and obstetrics: the official organ of the International Federation of Gynaecology and Obstetrics 2006, 93(3):300-307.

10. Harvey SA, Blandón YCW, McCaw-Binns A, Sandino I, Urbina L, Rodríguez C, Gómez I, Ayabaca P, Djibrinaf S, group tNmanhqi: Are skilled birth attendants really skilled? A measurement method, some disturbing results and a potential way forward. Bull World Health Organ 2007, 85:783-790.

11. Olsen BE, Hinderaker SG, Bergsjø P, Lie RT, Olsen OHE, Gasheka P, Kvåle G: Causes and characteristics of maternal deaths in rural northern Tanzania. Acta Obstet Gynecol Scand 2002, 81(12):1101-1109.

12. Sepehri A, Sarma S, Simpson W, Moshiri S: How important are individual, household and commune characteristics in explaining utilization of maternal health services in Vietnam? Soc Sci Med 2008, 67:1009-1017.

13. Babalola S, Fatusi A: Determinants of use of maternal health services in Nigeria - looking beyond individual and household factors. BMC Pregnancy Childbirth 2009, 9(1):43.

14. Tsui A, Ukwuani F, Guilkey D, Angeles G: A Comparative multi-level analysis of health program effects on individual use of reproductive and sexual health services. MEASURE Evaluation Bulletin 2003, 6:1-12.

15. Kruk ME, Galea S, Prescott M, Freedman LP: Health care financing and utilization of maternal health services in developing countries. Health Policy Plan 2007, 22(5):303-310.

16. Parkhurst JO, Penn-Kekana L, Blaauw D, Balabanova D, Danishevski K, Rahman SA, Onama V, Ssengooba F: Health systems factors influencing maternal health services: a four-country comparison. Health Policy 2005, 73(2):127-138 
17. Turner AG, Angeles G, Tsui AO, Wilkinson M, Magnani R: Sampling Manual for Facility Surveys for Population, Maternal Health, Child Health and STD Programs in Developing Countries. In Manual Series. Chapel Hill: Carolina Population Center, University of North Carolina; 2001. No. 3.

18. COMMISSION FPC: Statistical Report of the, Population and Housing Census Results. Addis Ababa: UNFPA; 2007:2008.

19. Ethiopian Society of Population Studies: Maternal Health Care Seeking Behaviour in Ethiopia: In-depth Analysis of the Ethiopian Demographic and Health Survey 2005. Addis Ababa: Ethiopian Society of Population Studies; 2008.

20. Nigussie M, Mariam DH, Mitike G: Assessment of safe delivery service utilization among women of childbearing age in North Gondar Zone, North West Ethiopia. Ethiop J Heal Dev 2004, 18(3):145-152.

21. WHO: Antenatal care in developing countries: promises, achievements and missed opportunities: an analysis of trends, levels and differentials: 1990-2001. World Health Organization; 2003.

22. Chandhiok N, Dhillon BS, Kambo I, Saxena NC: Determinants of antenatal care utilization in rural areas of India: A cross-sectional study from 28 districts. The Journal of Obstetrics and Gynecology of India 2006, 56(1):47-52.

23. Karim A, Betemariam W, Yalew S, Alemu H, Carnell M, Mekonnen Y: Programmatic correlates of maternal healthcare seeking behaviors in Ethiopia. Ethiop J Heal Dev 2010, 24(1):92-99.

24. Wirth M, Sacks E, Delamonica E, Storeygard A, Minujin A, Balk D: "Delivering" on the MDGs? equity and maternal health in Ghana, Ethiopia and Kenya. East Afr J Public Health 2008, 5(3):133-141.

25. Chakraborty N, Islam MA, Chowdhury Rl, Bari W, Akhter HH: Determinants of the use of maternal health services in rural Bangladesh. Health Promot Int 2003, 18(4):327-337.

26. Stanton C, Blanc AK, Croft T, Choi Y: Skilled care at birth in the developing world: progress to date and strategies for expanding coverage. J Biosoc Sci 2007, 39(1):109-120

27. Prata N, Greig F, Walsh J, West A: Ability to pay for maternal health services: what will it take to meet who standards? Health Policy 2004, 70(2):163-174

doi:10.1186/1472-698X-13-20

Cite this article as: Worku et al:: Factors affecting utilization of skilled maternal care in Northwest Ethiopia: a multilevel analysis. BMC International Health and Human Rights 2013 13:20.

\section{Submit your next manuscript to BioMed Central and take full advantage of:}

- Convenient online submission

- Thorough peer review

- No space constraints or color figure charges

- Immediate publication on acceptance

- Inclusion in PubMed, CAS, Scopus and Google Scholar

- Research which is freely available for redistribution 